\title{
Diagnosis and treatment of iron deficiency anemia in patients with inflammatory bowel disease and gastrointestinal bleeding: iron deficiency anemia working group consensus report
}

Hale Akpınar', Mustafa Çetiner², Satish Keshav³, Necati Örmeci, Murat Törüner

'Department of Gastroenterology, Dokuz Eylül University School of Medicine, İmir, Turkey

${ }^{2}$ Department of Hematology, Koç University School of Medicine American Hospital, İstanbul, Turkey

${ }^{3}$ Department of Gastroenterology, Oxford University Faculty of Medicine John Radcliffe Hospital, Oxford, England

${ }^{4}$ Department of Gastroenterology, Ankara University School of Medicine, Ankara, Turkey

\begin{abstract}
Iron deficiency (ID) and iron deficiency anemia (IDA) are important signs of gastrointestinal (GI) hemorrhage. Therefore, the evaluation of the Gl tract should be a part of the diagnostic protocol in patients with IDA. GI hemorrhage is not a disease but a symptom, which might have different underlying causes. ID and IDA have significant negative impacts on the life quality and work ability, and they may lead to frequent hospitalization, delay of discharge, and increased healthcare costs. Therefore, an optimal management of the disease causing GI hemorrhage should include iron replacement therapy, along with the treatment of the underlying condition. IDA in inflammatory bowel disease (IBD) has received particular attention owing to its high prevalence, probably due to a number of other factors such as chronic hemorrhage, reduced dietary iron intake, and impaired absorption of iron. Historically, in IBD and in patients with Gl hemorrhage, the diagnosis and management of IDA have been suboptimal. Options for iron replacement include oral and intravenous (IV) iron supplementation. Oral iron supplementation frequently results in GI side effects, and theoretically, it may exacerbate IBD activity; therefore, IV iron supplementation is usually considered in patients not responding to or not complying with oral iron supplementation or patients having low hemoglobin concentration and requiring prompt iron repletion. The aim of this report was to review the diagnostic and therapeutic considerations of IDA in IBD and GI hemorrhage with a multidisciplinary group of experts and to formulate necessary practical recommendations.

Keywords: Inflammatory bowel disease, gastrointestinal hemorrhage, iron deficiency anemia, oral administration, intravenous administration
\end{abstract}

\section{INTRODUCTION}

Iron deficiency anemia (IDA) is of prime concern to gastroenterologists owing to its prevalent gastrointestinal etiology. Both overt and occult gastrointestinal (GI) hemorrhages are the most common causes for IDA in adults, and they often require an endoscopic evaluation. Gl tract lesions and occult bleeding might account for a daily iron loss of 1-2 mg. There are many possible causes of $\mathrm{Gl}$ hemorrhage, which include esophageal varices, peptic ulcer, gastritis, polyps, angiodysplasia, diverticular disease, inflammatory bowel disease (IBD), hemorrhoids, anal fissure, and cancer (1). IBD is a chronic Gl disorder involving Crohn's disease (CD) and ulcerative colitis (UC), and it is characterized by periods of relapse and remission. IDA, depending on other factors, occurs in about 17\%-76\% IBD patients, and it is the most frequently documented extraintestinal manifestation and clinical complication. IDA is associated with poor quality of life, frequent hospitalization, and increased mortality rates. In addition, it increases the likelihood of allogeneic blood transfusions in hospitalized patients and the associated adverse events (ADEs) and outcomes related to blood transfusions (2). Therefore, in patients with IBD and GI hemorrhage, the accurate diagnosis and management of IDA are crucial (1-5).

In this report, a Medline search was conducted for the literature published between 2000 and 2016 by using the 


\section{Akpınar et al. Iron deficiency anemia in inflammatory bowel disease and gastrointestinal bleeding}

keywords "inflammatory bowel disease," "gastrointestinal hemorrhage," "iron deficiency anemia," "oral administration," and "intravenous administration" in order to select the ones regarding the diagnosis and management of IDA in IBD and in Gl hemorrhage. Reference lists of the included articles were also perused for additional related literature. The articles regarding macrocytic anemias were excluded. Conclusive recommendations are suggested by the group of experts at the end of every section.

\section{Anemia in IBD}

The primary forms of hypochromic microcytic anemias in IBD include iron deficiency anemia (IDA), anemia of chronic disease (ACD), and anemia of mixed origin (AMO). Macrocytic anemias caused by the deficiency of cobalamin and folic acid might also be contributors. Although the significance of anemia in patients with IBD is well understood due to its high prevalence, it remains potentially underdiagnosed and often inadequately treated $(4,6)$. Several recent studies show that anemia is highly prevalent in IBD. Høivik et al. (7) conducted a population-based study including 756 patients (237 with CD and 519 with UC) and reported that $48.8 \%$ of CD and $20.2 \%$ of UC patients were anemic at the diagnosis stage. In another population-based study, Sjöberg et al. (8) found the prevalence of anemia in 749 IBD patients as 30\% (CD: 42\%; UC: $24 \%$ ) at the time of diagnosis. Toruner et al. (9) reported the prevalence of anemia in a total of 398 patients with IBD (186 with CD and 212 with UC) as $22 \%$ in UC patients and $24 \%$ in CD patients in a single-center cohort study. In a cohort of a patient with IBD spanning 18 years, the incidence rate of anemia was reported for the first time by Atug et al. (10) The records of 941 IBD patients ( 375 with CD and 566 with UC) were obtained and anemia was found in 548 (58.2\%) patients (62.1\% of $C D$ and $55.7 \%$ of UC). In the cohort of all the patients with IBD, the incidence rate of anemia was determined as 103.45 per 1,000 patients in each year. Koutroubakis et al. (11) reported that the prevalence of anemia was $50.1 \%$ (CD: $53.3 \%$; UC: $44.7 \%$ ) in 1,821 IBD patients ( 1,077 with CD and 744 with UC). Serum ferritin levels were available for 287 (15.8\%) patients with IBD; further, definite IDA with ferritin levels of $<30 \mu \mathrm{g} / \mathrm{L}$ were observed in $46.5 \%$ patients. Similarly, Filmann et al. (12) reported the overall prevalence of anemia as 24\% (CD: 27\%; UC: 21\%) in 2,192 IBD patients (1,210 with CD and 981 with UC); further, $57 \%$ anemic patients were iron deficient in this meta-analysis. There are two main reasons of IDA in IBD. First, increased iron loss due to acute/ chronic blood loss and second, decreased iron absorption due to inadequate diet, inflammation, or surgery (13-16).

\section{Anemia in GI Hemorrhage}

Gastrointestinal hemorrhage is a common medical problem, which may present acutely as an emergency, or even sometimes chronically. In most cases, IDA is a potential problem in these cases. Bager et al. performed a retrospective evaluation of patients admitted for acute upper GI hemorrhage. In this study, the retrospective data of 169 patients were included. The prevalence of anemia in the patients who were discharged was $82 \%$. Among them, only $16 \%$ were advised to take iron supplements after discharge. In patients with frequent episodes of Gl hemorrhage, such as those with IBD, the iron level should be monitored regularly after $\mathrm{Gl}$ hemorrhage is resolved as common bleeding may cause the depletion of iron stores in the body (16-18).

\section{Recommendation}

* Patients with IBD and GI hemorrhage should be tested for an episode of iron deficiency (ID) and IDA.

* Large-scale, multicenter studies should be performed in Turkey for accurate population-based data collection regarding IDA in patients with IBD and GI hemorrhage.

\section{Symptoms and Diagnostic Tools of Anemia in IBD and GI Hemorrhage}

The symptoms of anemia include fatigue, headache, dizziness, tachycardia, dyspnea, loss of libido, nausea, vertigo, tinnitus, weight loss, motility disorder, lethargy, and syncope, although patients may also remain asymptomatic or minimally symptomatic (13). ID without anemia may also result in the same symptoms or may be asymptomatic.

Danese et al. (19) employed an online questionnaire to investigate the patients' perceptions of anemia in IBD. A total of 631 patients completed the questionnaire. Most of them were familiar with anemia and believed that anemia in IBD occurs frequently or very frequently. They assumed that anemia in IBD is due to blood loss, ID, and inflammation. The main symptoms reported commonly by the patients with anemia were fatigue and weakness.

World Health Organization (WHO) defines anemia as low blood hemoglobin $(\mathrm{Hb})$ level, below the concentration of $13 \mathrm{~g} / \mathrm{dL}$ and $12 \mathrm{~g} / \mathrm{dL}$ in men and non-pregnant women, respectively. However, all differential diagnostic approaches should be considered and diagnostic tests should be performed to confirm the presence of anemia (Tables 1 and 2).

Under normal circumstances, serum ferritin level below $15 \mu \mathrm{g} / \mathrm{L}$ is an indicator of ID. On the other hand, as serum ferritin is an acute phase reactant, there is a strong correlation between the diagnostic criteria and the level of inflammation for ID. In patients without the evidence of an active disease, serum ferritin $<30 \mu \mathrm{g} / \mathrm{L}$ can be taken as a convenient parameter. In the presence of inflammation, the possibility of ID cannot be excluded when the serum ferritin level is $>100 \mu \mathrm{g} / \mathrm{L}$. Similarly, transferrin and iron-binding capacity also become unreliable since inflammation influences these parameters. In a condition such as IBD, further analyses may be required to confirm IDA, such as reticulocyte hemoglobin content, percentage of hypochromic red blood cells, transferrin saturation index, and zinc protoporphyrin, but these tests are not yet widely available (Table 3 ). Because of these challenges, it has been suggested that the patient should be referred to a hematologist for expert evaluation in the case of diagnostic uncertainties $(4,20,21)$. 
Table 1. Discriminatory characteristics of IDA, ACD and AMO (3)

\begin{tabular}{lccc}
\hline & $\begin{array}{c}\text { Iron } \\
\text { deficiency } \\
\text { anemia (IDA) }\end{array}$ & $\begin{array}{c}\text { Anemia of } \\
\text { chronic } \\
\text { disease (ACD) }\end{array}$ & $\begin{array}{c}\text { Anemia of } \\
\text { mixed } \\
\text { origin (AM0) }\end{array}$ \\
\hline Serum ferritin & $\downarrow$ & Nor $\uparrow$ & $N$ \\
Serum iron & $\uparrow$ & $\downarrow$ & $\downarrow$ \\
Transferrin & $\downarrow$ & $\downarrow$ or N & $\downarrow$ \\
Transferrin saturation & $\downarrow$ & $\downarrow$ & $\downarrow$ \\
Mean corpuscular volume & $\uparrow$ & $\downarrow$ & $\downarrow$ or N \\
Iron-binding capacity & $\uparrow$ & $\mathrm{N}$ & $\uparrow$ tor $\mathrm{N}$ \\
Serum transferrin receptor $\mathrm{N}$ & Low $(<1)$ & High $(>2)$ \\
Serum transferrin & High $(>2)$ & $\uparrow$ & $\uparrow$ \\
receptor index & $\mathrm{N}$ & N or slightly $\uparrow$ & $\uparrow$ or N \\
C-reactive protein & $\uparrow$ & $\uparrow$ & $\uparrow$ \\
Erythropoietin & $\mathrm{N}$ & & \\
Cytokine levels & & & \\
\hline N: normal & & & \\
\hline
\end{tabular}

Table 2. Tests for the diagnosis of IDA (3)

\begin{tabular}{|c|c|c|c|}
\hline Complete blood count & & Serum ferritin & Other \\
\hline $\begin{array}{l}\text { - Suggestive of } \\
\text { iron deficiency }\end{array}$ & 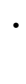 & $\begin{array}{l}\text { Diagnostic test } \\
\text { of choice }\end{array}$ & - Serum iron $\downarrow$ \\
\hline $\begin{array}{l}\text { - Not the diagnostic } \\
\text { test of choice }\end{array}$ & • & Adult levels ( $\mu \mathrm{g} / \mathrm{L})$ & $\begin{array}{l}\text { - Iron-binding } \\
\text { capacity } \uparrow\end{array}$ \\
\hline \multirow[t]{3}{*}{$\begin{array}{l}\text { Hemoglobin } \\
\text { threshold: men } \\
<13 \mathrm{~g} / \mathrm{dL} \text {; non- } \\
\text { pregnant women } \\
<12 \mathrm{~g} / \mathrm{dL}\end{array}$} & & $\begin{array}{l}<15 \text { - diagnostic } \\
\text { for iron deficiency } \\
15-50 \text { - probable } \\
\text { iron deficiency } \\
50-100 \text { - possible } \\
\text { iron deficiency }\end{array}$ & $\begin{array}{l}\text { - Transferrin } \\
\text { saturation <16\% }\end{array}$ \\
\hline & & $\begin{array}{l}\text { >100 - iron } \\
\text { deficiency unlikely }\end{array}$ & \\
\hline & & $\begin{array}{l}\text { Persistently }>1000 \text { - } \\
\text { iron overload? }\end{array}$ & \\
\hline
\end{tabular}

Table 3. Advanced diagnostic tests for IDA (20)

\begin{tabular}{lcccc}
\hline Laboratory Measures & Normal & IDA & ACD & IDA/ACD \\
\hline${ }^{*}$ STfR-F index & $\uparrow(>2)$ & $\uparrow(>2)$ & $\downarrow(<1)$ & $\uparrow(>2)$ \\
$\mathrm{CHr}$ & $\geq 29 \mathrm{pg}$ & $\downarrow \downarrow$ & $\mathrm{N}$ or $\downarrow$ & $\downarrow$ \\
PHRC & $1-5 \%$ & $>5 \%$ & $<5 \%$ & \\
*Zinc protoporphyrin & $<40(\mathrm{\mu mol} / \mathrm{mol}$ heme) & $>80$ & $\geq 80$ & $\geq 80$ \\
C-reactive protein & $<5 \mathrm{mg} / \mathrm{L}$ & $\mathrm{N}$ & $\uparrow \uparrow$ & $\uparrow$ \\
\hline
\end{tabular}

*Values vary according to different assays

IDA: iron deficiency anemia; ACD: anemia of chronic disease; Chr: Reticulocyte hemoglobin content; PHRC: Percentage of hypochromic erythrocytes; sTfR-F: Soluble transferrin receptor-ferritin; N: normal

\section{Recommendation}

* The diagnosis of IDA should be confirmed by the means of differential diagnostic tests prior to the treatment.

* Refer the patient to a hematologist if the reason of anemia remains uncertain after further examinations.

\section{Treatment of Anemia due to IBD and GI Hemorrhage}

Although IDA may be a consequence of active IBD, the treatment of the underlying disease does not necessarily correct IDA, which remains highly prevalent. For this reason, it is necessary to directly treat IDA.

The aim of iron supplementation in IDA is to elevate the levels of hemoglobin $(\mathrm{Hb}>2 \mathrm{~g} / \mathrm{dL})$, attain normal $\mathrm{Hb}$ levels within 4 weeks, enhance ferritin levels (transferrin saturation $>30 \%$ ), relieve the symptoms of anemia, and therefore, improve the quality of life.

There are two administration routes of iron: oral and intravenous (IV). Oral iron supplementation is the conventional method in the management of IDA; however, it has been found to be associated with Gl side effects, adherence problems, and insufficient effectiveness. In certain cases, it may potentially exacerbate the disease through the formation of reactive oxygen species. However, the use of IV iron is still a matter of concern among many physicians, despite new-generation IV iron preparations with improved safety profiles and proper recommended guidelines (see IV iron preparations available in Turkey as listed in Table 4).

There are two treatment approaches available for the management of IDA in IBD: i) Oral iron administration if the patient has mild-to-moderate anemia $(\mathrm{Hb}>10 \mathrm{~g} / \mathrm{dL})$, if the disease is inactive (C-reactive protein $(C R P)<5 \mathrm{mg} / \mathrm{L}$ ), and if there is good tolerance, adherence, and sufficient response $(\mathrm{Hb}>2 \mathrm{~g} / \mathrm{dL}$ in 4 weeks); ii) Direct initiation of IV iron therapy regardless of $\mathrm{Hb}$ and CRP levels (3, 13-15, 20-24).

In a recently published meta-analysis by Bonovas et al. (25), integrated evidence from randomized controlled trials showed that IV administration of iron is more effective than oral iron uptake in achieving hemoglobin rise of $\geq 2.0 \mathrm{~g} / \mathrm{dL}$, and it is better tolerated as compared to oral iron in IBD. In another metaanalysis by Tolkien et al. (26) oral iron (ferrous sulfate) resulted in remarkable Gl side effects in adults when compared to either placebo or IV iron. The results of a randomized, controlled, open-label, multicenter study suggested that IV iron sucrose (IS) had a better GI safety profile in comparison to oral iron sulfate, and 5 patients (20.8\%) in the oral group and 1 patient (4.5\%) in the IV group discontinued the drug due to adverse GI ADEs. Furthermore, only IV iron led to an increase in serum ferritin concentrations (27). In another randomized controlled study, ferric carboxymaltose (FCM) IV and oral iron sulfate were compared. The administration of FCM up to $1,000 \mathrm{mg}$ iron 
Table 4. IV iron preparations available in Turkey $(14,16,20,22,36)$

\begin{tabular}{|c|c|c|c|}
\hline & $\begin{array}{l}\text { Low-molecular- } \\
\text { weight iron } \\
\text { dextran (LMWID) }\end{array}$ & $\begin{array}{l}\text { Iron } \\
\text { sucrose } \\
\text { (IS) }\end{array}$ & $\begin{array}{c}\text { Ferric } \\
\text { carboxymaltose } \\
\text { (FCM) }\end{array}$ \\
\hline Molecular weight (kD) & 165 & 43.3 & 150 \\
\hline Complex stability & High & Moderate & High \\
\hline Dose of elemental iron & $50 \mathrm{mg} / \mathrm{mL}$ & $20 \mathrm{mg} / \mathrm{mL}$ & $50 \mathrm{mg} / \mathrm{mL}$ \\
\hline Test dose required & Yes & No & No \\
\hline $\begin{array}{l}\text { Routes of } \\
\text { administration }\end{array}$ & $\begin{array}{l}\text { Slow IV injection } \\
\text { IV infusion }\end{array}$ & $\begin{array}{l}\text { Slow IV injection } \\
\text { IV infusion }\end{array}$ & $\begin{array}{l}\text { Slow IV injection } \\
\text { IV infusion }\end{array}$ \\
\hline $\begin{array}{l}\text { Able to administer } \\
\text { total dose }\end{array}$ & $\begin{array}{l}\text { Yes (up to } 20 \\
\mathrm{mg} / \mathrm{kg} \text { body } \\
\text { weight over } \\
4-6 \text { hours) }\end{array}$ & No & $\begin{array}{l}\text { Yes (up to } \\
20 \mathrm{mg} / \mathrm{kg} \\
\text { body weight } \\
\text { maximum of } \\
1000 \text { mg/week } \\
\text { over } 15 \mathrm{~min} \text { ) }\end{array}$ \\
\hline Half-life & 5 hours & 20 hours & $7-12$ hours \\
\hline Dosage & $\begin{array}{l}\text { 100-200 mg per IV } \\
\text { injection up to } \\
3 \text { times a week. } \\
\text { Total dose infusion } \\
\text { up to } 20 \text { mg/kg } \\
\text { body weight over } \\
\text { 4-6 hours). }\end{array}$ & $\begin{array}{c}\text { Total IV } \\
\text { single dose no } \\
\text { more than, } \\
200 \text { mg can } \\
\text { be repeated } \\
\text { up to } 3 \text { times } \\
\text { in one week. }\end{array}$ & $\begin{array}{c}1000 \text { mg by IV } \\
\text { injection up to } \\
15 \mathrm{mg} / \mathrm{kg} / \text { week. } \\
\text { Total dose infusion } \\
\text { up to } 20 \mathrm{mg} / \mathrm{kg} \\
\text { body weight. } \\
\text { Maximum } \\
\text { weekly dose } \\
\text { of } 1000 \mathrm{mg} \\
\text { that can be } \\
\text { administered } \\
\text { over } 15 \text { min. }\end{array}$ \\
\hline
\end{tabular}

Adverse drug-

related events

Moderate

Very low

Very low

within 15 min was found to be effective in the treatment of IBDassociated anemia. FCM was not inferior to iron sulfate in terms of $\mathrm{Hb}$ variation over 12 weeks, and it also resulted in a rapid elevation of $\mathrm{Hb}$ levels and refilling of iron stores with few relevant side effects (28). Lindgren et al. (29) conducted a randomized, controlled, evaluator-blind, multicenter study, and the results showed that IV IS treatment is superior to oral iron sulphate in the improvement of $\mathrm{Hb}$ and iron stores in patients with IBD; further, IS has better GI tolerance. Avni et al. (30) compared the treatment methods for anemia in patients with IBD in a systematic review and carried out a meta-analysis of randomized controlled trials. The study concluded that the treatment of anemia in IBD should include IV administration of iron, but not oral iron replacement, due to its curative effect on $\mathrm{Hb}$ response, lack of toxicity, and negative effect on the disease activity. FERGlcor was a randomized controlled, open-label, multicenter study that included 485 patients with IDA and IBD. The patients received either FCM (three or fewer infusions of $500 \mathrm{mg}$ or 1000 mg iron, or Ganzoni-calculated IS dosages (maximum 11 infusions of $200 \mathrm{mg}$ iron). Both treatments improved the quality of life scores, but the simpler FCM-based dosing regimen showed superior efficacy and compliance when compared with the Ganzoni-calculated IS dosing, and the lower number of infu- sions increases the convenience and cost-effectiveness of IV iron supplementation (31). Similarly, Bager et al. (32) reviewed 111 IBD patients' data and compared IS and FCM through costbenefit, cost-effective, and budget impact analyses. FCM was found to be advantageous according to the cost-benefit and cost-effective analyses. In another pharmacoeconomic analysis conducted at a Gl diseases unit, 111 patients' records that received IV iron were evaluated in terms of the number of infusions and the dose of iron, and the total costs of IS and FCM were compared. In conclusion, FCM was favored over IS (33).

The recurrence of anemia in IBD patients after treatment is another important issue. In a retrospective study conducted by Kulnigg et al. (34), it was reported that the median value of ID recurrence within 19 months was the indicator of the requirement of maintenance therapy. The recurrence rate was higher in patients with low post-treatment ferritin levels $(<100 \mu \mathrm{g} / \mathrm{L}$; median: 4 months) than those in a normal ferritin range (100$400 \mu \mathrm{g} / \mathrm{L}$; median: 11 months) and with higher ferritin levels (400 $\mu \mathrm{g} / \mathrm{L}$; median: 49 months). Therefore, the aim of iron replacement should be to achieve a post-treatment ferritin level of at least $400 \mu \mathrm{g} / \mathrm{L}$ (upper safety limit: $800 \mu \mathrm{g} / \mathrm{L}$ ), and patients should be followed-up regularly to delay or avoid the recurrence of ID. Evstatiev et al. (35) performed a multicenter, randomized, placebo-controlled trial to determine if the administration of FCM prevents anemia in patients with IBD. They concluded that in comparison to placebo, FCM is much more effective and safer for the prevention of recurrent anemia.

An analysis involving complete blood count, serum ferritin, and CRP should be performed during the follow-up of patients. Patients who are in remission or have a mild disease course should be repeatedly monitored every 6 to 12 months, and those with active disease should be monitored at least every 3 months. The serum levels of cobalamin and folic acid should be measured at least annually or in the presence of macrocytosis. The target values of IV iron replacement therapy should be up to $400 \mu \mathrm{g} / \mathrm{L}$. After the successful treatment of IDA with IV iron supplementation, IV iron therapy should be reinitiated as soon as the serum ferritin level drops $<100 \mu \mathrm{g} / \mathrm{L}$ (4).

\section{Safety of IV Iron Treatment}

\section{Recommendation}

The goal of IDA therapy is to increase hemoglobin levels by $>2 \mathrm{~g} / \mathrm{dL}$ within 4 weeks and to refill iron stores.

* The target values of IV iron replacement therapy should be up to $400 \mu \mathrm{g} / \mathrm{L}$.

* In patients with IBD, when compared with oral iron therapy, IV iron supplementation refills the depleted iron stores more effectively.

* The major misconceptions are high doses of oral iron administration resolve the problem of iron malabsorption in IBD, and IV iron is useful only for severe anemia. 
* Serum iron and ferritin levels should be evaluated regularly in the purview of IDA recurrence.

* If ferritin levels are $<100 \mu \mathrm{g} / \mathrm{L}$, iron replacement therapy should be performed on patients before they develop anemia.

* In the light of the literature and clinical experience of IDA working group, direct IV iron initiation is recommended to treat IDA in patients with IBD, regardless of anemia severity and IBD activity.

* Refer the patient to a hematologist if there is no response to treatment.

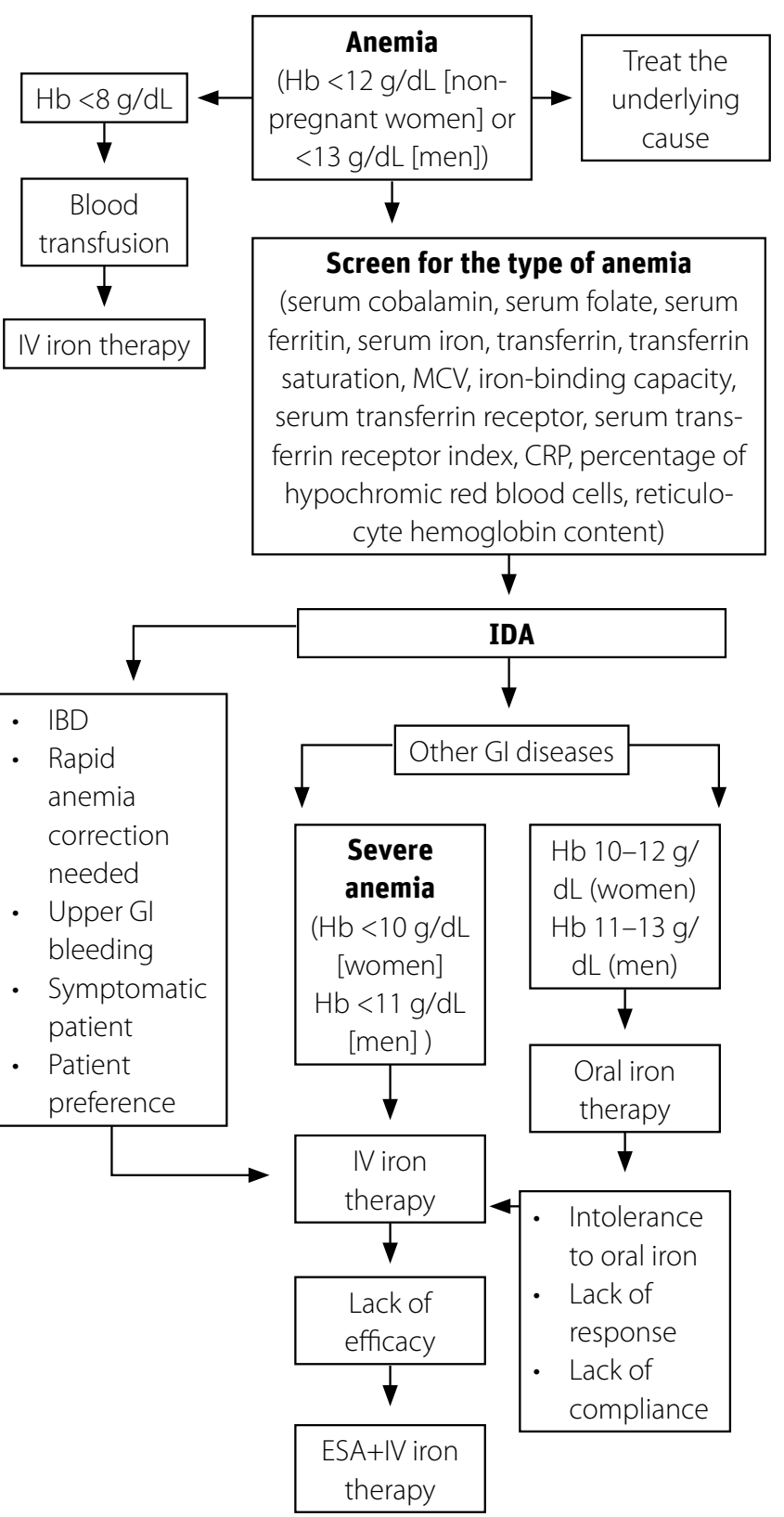

Figure 1. Algorithm for the diagnosis and treatment of IDA in patients with Gl diseases

$\mathrm{Hb}$ : hemoglobin; IDA: iron deficiency anemia; MCV: mean corpuscular volume; CRP: Creactive protein; IBD: irritable bowel disease; GI: gastrointestinal; IV: intravenous; ESA: erythropoiesis-stimulating agent
Safety concerns regarding parenteral iron preparations are associated with serious ADEs (anaphylaxis, shock, and death), which are predominantly reported with the use of high-molecular-weight iron dextran that is no longer available in European markets. The safety profiles of the latest preparations, such as IS and FCM, are more favorable (36).

Chertow et al. (37) conducted a study by using the data of US FDA's Medwatch programme, and they determined that the frequency of IV ADEs associated with iron is comparatively reduced, and the overall rates are extremely low. The increased risks are related to the use of high-molecular-weight iron dextran.

Among the iron preparations, IS has the most extensive dataset as an outcome of extensive research. In the study by Van Wyck et al. (38), it was concluded that IS injection is a safe and effective method in the management of anemia in patients who are sensitive to iron dextran, and it can be administered without a test dose by IV push or infusion.

Ferric carboxymaltose is a new IV iron preparation, which has been reported to be equally safe and more effective than IS. Since FCM is a highly stable compound and renders low toxicity, the conditions that are relevant to its use, such as unstable iron release or liver necrosis, are not observed. It also has a very low risk of anaphylaxis or anaphylactoid reaction as there is no dextran. FCM allows higher doses of iron to be administered in a short period of time; therefore, it is possible to prevent issues associated with patient compliance and the additional cost of multiple administrations. Information about the experience with FCM is gradually increasing $(36,39,40)$.

In a study considering a large number of patients (almost 2000 patients treated with IV FCM versus 800 patients treated with oral iron), FCM was generally well tolerated as it yielded lower incidence of Gl side effects and low risk of hypersensitivity reactions. FCM improved the replenishment of iron stores, and therefore, anemia in various populations with IDA, including patients with chronic kidney disease, IBD, heavy uterine bleeding, postpartum IDA, and perioperative anemia. The most common laboratory abnormality in patients treated with FCM was transient and asymptomatic hypophosphatemia with unknown clinical etiology (41).

Physicians should also be aware of the Fishbane reaction, which is characterized by transient flushing and truncal myalgia with joint pain. It is similar to anaphylactoid reaction without hypotension and tachycardia, but it is not actually immunological. The symptoms abate spontaneously over a few minutes and do not usually recur on rechallenge (42).

A recent study from 55 gastroenterological centers showed that only $43.5 \%$ anemic IBD patients were treated for anemia (43). In another study from 9 European countries, the majority of IBD patients with anemia were treated with oral iron (67\%), whereas only $28 \%$ received IV iron (44). In clinical prac- 


\section{Akpınar et al. Iron deficiency anemia in inflammatory bowel disease and gastrointestinal bleeding}

tices, most IBD patients with anemia either do not receive iron supplementation or receive oral iron despite existing evidence and international guidelines recommending IV administration as the preferred route $(4,23,45)$.

\section{Rationale for oral iron supplementation}

* Simple route to administer

* More data are available on treatment experience

* Rare lethal drug-related ADEs (anaphylaxis)

* Low cost

* Patient preference

\section{Rationale for IV iron supplementation}

* Fast results are received; more effective

* Repletion of iron stores regardless of factors affecting iron absorption

* High adherence and compliance

* Minimal side effects and high tolerability

* One-time administration (FCM and LMWID)

* No mucosal toxicity and disease exacerbation

* Patient preference

According to the literature and our experience, an approach for the diagnosis and treatment of IDA in patients with Gl diseases is illustrated in the figure.

\section{Recommendation}

* Misconception: IV iron is dangerous.

* New-generation IV iron preparations are more favorable for rapid infusion and there is no need for test dosing.

In conclusion, IDA remains the most common cause of anemia in patients with $\mathrm{Gl}$ hemorrhage and IBD. It significantly reduces the quality of life if not treated properly. The diagnosis of IDA can be challenging sometimes and choosing the appropriate tests and evaluating the outcomes in detail are essential. When routine diagnostic tests are insufficient, further diagnostic tests should be used if possible. Checking CRP levels is also important to rule out inflammation and to evaluate the activity of IBD. The current literature shows that IV iron supplementation is more effective than orally administered iron in curing IDA. Faster efficacy, higher tolerability, higher adherence, one-time administration (FCM and LMWID), and mucosal nontoxicity are other advantages of the IV route. However, many physicians, owing to their stubborn nature, are still insistent on using oral iron despite its side effects, compliance problems, slow repletion, and lack of response. They need to consider if they really want to treat the patient or to write a prescription without being interested in the outcomes.

Peer-review: Externally peer-reviewed.

Author Contributions: Concept - H.A., M.C., S.K., N.O., M.T.; Design - H.A., M.C., S.K., N.O., M.T; Supervision - H.A., M.C., S.K., N.O., M.T.; Resources - H.A., M.C., S.K., N.O., M.T.; Materials - H.A., M.C., S.K., N.O., M.T.; Data Collection
Turk J Gastroenterol 2017:28:81-7

and/or Processing - M.T.; Analysis and/or Interpretation - M.T.; Writing Manuscript - M.T.; Critical Review - H.A., M.C., S.K., N.O., M.T.; Other - M.T.

Acknowledgements: The authors are grateful to Figen Yavuz for her technical assistance and for help in data collecting anf manuscript preparation.

Conflict of Interest: No conflict of interest was declared by the authors.

Financial Disclosure: Satish Keshav has provided consultancy services for a number of pharmaceutical and healthcare companies including Abbvie, Actavis Allergan, Astra-Zeneca, Boehringer Ingelheim, ChemoCentryx, Dr. Falk Pharma, Ferring, Gilead, GSK, Merck, Mitsubishi Tanabe Pharma, Pharmacosmos, Pfizer, Takeda, and Vifor Pharma, and received research support from Abbvie, ChemoCentryx, GSK, and Merck.

\section{REFERENCES}

1. Zhu A, Kaneshiro M, Kaunitz JD. Evaluation and treatment of iron deficiency anemia: a gastroenterological perspective. Dig Dis Sci 2010; 55: 548-59. [CrossRef]

2. Shander A, Javidroozi M, Ozawa S, Hare GM. What is really dangerous: anaemia or transfusion? Br J Anaesth 2011; 107: i41-59. [CrossRef]

3. Goldberg ND. Iron deficiency anemia in patients with inflammatory bowel disease. Clin Exp Gastroenterol 2013; 6: 61-70. [CrossRef]

4. Dignass AU, Gasche C, Bettenworth D, et al. European consensus on the diagnosis and management of iron deficiency and anaemia in inflammatory bowel diseases. J Crohns Colitis 2015; 9: 211-22. [CrossRef]

5. Kaniewska M, Bartnik W, Gonciarz M, et al. Iron deficiency anaemia in patients with inflammatory bowel disease: National Consultant for Gastroenterology Working Group Recommendations. Prz Gastroenterol 2014; 9: 259-63. [CrossRef]

6. Guagnozzi D, Lucendo AJ. Anemia in inflammatory bowel disease: a neglected issue with relevant effects. World J Gastroenterol 2014; 20: 3542-51. [CrossRef]

7. Høivik ML, Reinisch W, Cvancarova M, Moum B; IBSEN study group. Anaemia in inflammatory bowel disease: a populationbased 10-year follow-up. Aliment Pharmacol Ther 2014; 39: 69-76. [CrossRef]

8. Sjöberg D, Holmström T, Larsson M, Nielsen AL, Holmquist L, Rönnblom A. Anemia in a population-based IBD cohort (ICURE): still high prevalence after 1 year, especially among pediatric patients. Inflamm Bowel Dis 2014; 20: 2266-70. [CrossRef]

9. Toruner M, Kalkan C, Keskin O, Cetinkaya H, Soykan I. P599. Prevalence of iron deficiency anemia and iron deficiency in a single center Turkish IBD cohort. J Crohns Colitis 2014; 8: S318-9. [CrossRef]

10. Atug $\mathrm{O}$, Kani HT, Banzragch $M$, Imeryuz N, Akın H. Incidence rate of anemia in inflammatory bowel diseases. Turk J Gastroenterol 2016; 27: 143-8. [CrossRef]

11. Koutroubakis IE, Ramos-Rivers C, Regueiro M, et al. Five-year period prevalence and characteristics of anemia in a large US inflammatory bowel disease cohort. J Clin Gastroenterol 2016; 50: 638-43. [CrossRef]

12. Filmann N, Rey J, Schneeweiss S, et al. Prevalence of anemia in inflammatory bowel diseases in european countries: a systematic review and individual patient data meta-analysis. Inflamm Bowel Dis 2014; 20: 936-45. [CrossRef] 
13. Kaitha S, Bashir M, Ali T. Iron deficiency anemia in inflammatory bowel disease. World J Gastrointest Pathophysiol 2015; 6: 62-72.

14. Stein J, Hartmann F, Dignass AU. Diagnosis and management of iron deficiency anemia in patients with IBD. Nat Rev Gastroenterol Hepatol 2010; 7: 599-610. [CrossRef]

15. Nielsen $\mathrm{OH}$, Ainsworth M, Coskun M, Weiss G. Management of Iron-Deficiency Anemia in Inflammatory Bowel Disease: A Systematic Review. Medicine (Baltimore) 2015; 94: e963. [CrossRef]

16. Bayraktar UD, Bayraktar S. Treatment of iron deficiency anemia associated with gastrointestinal tract diseases. World J Gastroenterol 2010; 16: 2720-5. [CrossRef]

17. Bager P. Fatigue and acute/chronic anaemia. Dan Med J 2014; 61: B4824.

18. Bager P, Dahlerup JF. Lack of follow-up of anaemia after discharge from an upper gastrointestinal bleeding centre. Dan Med J 2013; 60: A4583.

19. Danese S, Hoffman C, Vel S, et al. Anaemia from a patient perspective in inflammatory bowel disease: results from the European Federation of Crohn's and Ulcerative Colitis Association's online survey. Eur J Gastroenterol Hepatol 2014; 26: 1385-91. [CrossRef]

20. Stein J, Dignass AU. Management of iron deficiency anemia in inflammatory bowel disease - a practical approach. Ann Gastroenterol 2013; 26: 104-13.

21. Gisbert JP, Gomollón F. Common misconceptions in the diagnosis and management of anemia in inflammatory bowel disease. Am J Gastroenterol 2008; 103: 1299-307. [CrossRef]

22. Reinisch W, Staun M, Bhandari S, Mu-Oz M. State of the iron: how to diagnose and efficiently treat iron deficiency anemia in inflammatory bowel disease. J Crohns Colitis 2013; 7: 429-40. [CrossRef]

23. Gasche C, Berstad A, Befrits R, et al. Guidelines on the diagnosis and management of iron deficiency and anemia in inflammatory bowel diseases. Inflamm Bowel Dis 2007; 13: 1545-53. [CrossRef]

24. Gasche C, Lomer MC, Cavill I, Weiss G. Iron, anaemia, and inflammatory bowel diseases. Gut 2004; 53: 1190-7. [CrossRef]

25. Bonovas S, Fiorino G, Allocca M, et al. Intravenous Versus Oral Iron for the Treatment of Anemia in Inflammatory Bowel Disease: A Systematic Review and Meta-Analysis of Randomized Controlled Trials. Medicine (Baltimore) 2016; 95: e2308. [CrossRef]

26. Tolkien Z, Stecher L, Mander AP, Pereira DI, Powell JJ. Ferrous sulfate supplementation causes significant gastrointestinal side-effects in adults: a systematic review and meta-analysis. PLoS One 2015; 10: e0117383. [CrossRef]

27. Schröder $\mathrm{O}$, Mickisch $\mathrm{O}$, Seidler $\mathrm{U}$, et al. Intravenous iron sucrose versus oral iron supplementation for the treatment of iron deficiency anemia in patients with inflammatory bowel disease--a randomized, controlled, open-label, multicenter study. Am J Gastroenterol 2005; 100: 2503-9. [CrossRef]

28. Kulnigg S, Stoinov S, Simanenkov $V$, et al. A novel intravenous iron formulation for treatment of anemia in inflammatory bowel disease: the ferric carboxymaltose (FERINJECT) randomized controlled trial. Am J Gastroenterol 2008; 103: 1182-92. [CrossRef]

29. Lindgren S, Wikman O, Befrits R, et al. Intravenous iron sucrose is superior to oral iron sulphate for correcting anaemia and restoring iron stores in IBD patients: A randomized, controlled, evaluatorblind, multicentre study. Scand J Gastroenterol 2009; 44: 838-45. [CrossRef]
30. Avni T, Bieber A, Steinmetz T, Leibovici L, Gafter-Gvili A. Treatment of anemia in inflammatory bowel disease--systematic review and meta-analysis. PLoS One 2013; 8: e75540. [CrossRef]

31. Evstatiev R, Marteau P, lqbal T, et al. FERGIcor, a randomized controlled trial on ferric carboxymaltose for iron deficiency anemia in inflammatory bowel disease. Gastroenterology 2011; 141: 846853.e1-2.

32. Bager $\mathrm{P}$, Dahlerup JF. The health care cost of intravenous iron treatment in IBD patients depends on the economic evaluation perspective. J Crohns Colitis 2010; 4: 427-30. [CrossRef]

33. Calvet $X$, Ruíz MA, Dosal $A$, et al. Cost-minimization analysis favours intravenous ferric carboxymaltose over ferric sucrose for the ambulatory treatment of severe iron deficiency. PLoS One 2012; 7: e45604. [CrossRef]

34. Kulnigg S, Teischinger $L$, Dejaco C, Waldhör T, Gasche C. Rapid recurrence of IBD-associated anemia and iron deficiency after intravenous iron sucrose and erythropoietin treatment. Am J Gastroenterol 2009; 104: 1460-7. [CrossRef]

35. Evstatiev R, Alexeeva O, Bokemeyer B, et al. Ferric carboxymaltose prevents recurrence of anemia in patients with inflammatory bowel disease. Clin Gastroenterol Hepatol 2013; 11: 269-77. [CrossRef]

36. Api O, Breyman C, Cetiner M, Demir C, Ecder T. Diagnosis and Treatment of Iron Deficiency Anemia during Pregnancy and the Postpartum Period: Iron Deficiency Anemia Working Group Consensus Report. Turk J Obstet Gynecol 2015; 12: 173-81. [CrossRef]

37. Chertow GM, Mason PD, Vaage-Nilsen O, Ahlmén J. Update on adverse drug events associated with parenteral iron. Nephrol Dial Transplant 2006; 21: 378-82. [CrossRef]

38. Van Wyck DB, Cavallo G, Spinowitz BS, et al. Safety and efficacy of iron sucrose in patients sensitive to iron dextran: North American clinical trial. Am J Kidney Dis 2000; 36: 88-97. [CrossRef]

39. Keshav S, Anker S, Breymann C. 1st European Iron Academy Report (Barcelona, Spain) 2014 March 3-4 pp 1-12. Available from: http://www.europeanironacademy.com/2014/pagePlenarySession.html.

40. Barish CF, Koch T, Butcher A, Morris D, Bregman DB. Safety and Efficacy of Intravenous Ferric Carboxymaltose $(750 \mathrm{mg}$ ) in the Treatment of Iron Deficiency Anemia: Two Randomized, Controlled Trials. Anemia 2012; 2012: 172104. [CrossRef]

41. Keating GM. Ferric carboxymaltose: a review of its use in iron deficiency. Drugs 2015; 75: 101-27. [CrossRef]

42. Rampton D, Folkersen J, Fishbane S, et al. Hypersensitivity reactions to intravenous iron: guidance for risk minimization and management. Haematologica 2014; 99: 1671-76. [CrossRef]

43. Blumenstein I, Dignass A, Vollmer S, Klemm W, Weber-Mangal S, Stein J. Current practice in the diagnosis and management of IBDassociated anaemia and iron deficiency in Germany: the German AnaemIBD Study. J Crohns Colitis 2014; 8: 1308-14. [CrossRef]

44. Stein J, Bager P, Befrits R, et al. Anaemia management in patients with inflammatory bowel disease: routine practice across nine European countries. Eur J Gastroenterol Hepatol 2013; 25: 145663. [CrossRef]

45. Lee TW, Kolber MR, Fedorak RN, van Zanten SV. Iron replacement therapy in inflammatory bowel disease patients with iron deficiency anemia: a systematic review and meta-analysis. J Crohns Colitis 2012; 6: 267-75.[CrossRef] 